\title{
Effects of Microalloying on Stretch-flangeability of Ultrahigh- strength TRIP-aided Martensitic Steel Sheets
}

\author{
Duc Van PHAM, ${ }^{1)}$ Junya KOBAYASHI2)* and Koh-ichi SUGIMOTO ${ }^{3)}$ \\ 1) Graduate School of Shinshu University, 4-17-1 Wakasato, Nagano, 380-8553 Japan. \\ 2) Research Fellow of Japan \\ Society for the Promotion of Science, Graduate School of Shinshu University, 4-17-1 Wakasato, Nagano, $380-8553$ Japan. \\ 3) Department of Mechanical Systems Engineering, Faculty of Engineering, Shinshu University, 4-17-1 Wakasato, Nagano, \\ 380-8553 Japan.
}

(Received on February 12, 2014; accepted on April 28, 2014; originally published in Tetsu-to-Hagané, Vol. 99, 2013, No. 11, pp. 659-668)

\begin{abstract}
The effects of $\mathrm{Cr}, \mathrm{Mo}$, and $\mathrm{Ni}$ addition on the microstructure and stretch-flangeability of a $0.2 \% \mathrm{C}-$ $1.5 \% \mathrm{Si}-1.5 \% \mathrm{Mn}-0.05 \% \mathrm{Nb}$ (mass\%) transformation-induced plasticity (TRIP)-aided martensitic steel sheet produced by an isothermal transformation process at a temperature below martensite transformation-finish temperatures were investigated in order to develop third-generation steel sheet for automobiles requiring high hardenability. When $0.5 \%$ or $1.0 \% \mathrm{Cr}$ was added to the base steel, a tensile strength of $1.5 \mathrm{GPa}$ and a hole-expanding ratio of $40 \%$ was attained. On the other hand, the addition of $\mathrm{Cr}-\mathrm{Mo}$ or $\mathrm{Cr}-\mathrm{Mo}-\mathrm{Ni}$ had a minimal influence on stretch-flangeability and stretch-formability, although it increased the yield and tensile strengths as compared to the base steel. The good balance of the Cr-bearing steel was mainly caused by a suitable combination of (1) volume fraction and (2) interparticle path of a finely dispersed martensiteaustenite complex phase, which suppressed void initiation at the matrix/complex-phase interface on holepunching and void coalescence or crack extension on hole-expanding.
\end{abstract}

KEY WORDS: stretch-flangeability; microalloying; ultrahigh-strength steel; TRIP-aided steel; retained austenite; martensite.

\section{Introduction}

Recently, third-generation advanced high-strength steel sheets (third-generation AHSSs) have been developed for reducing the body weight of automobiles, suppressing global warming, and improving impact safety. Typical AHSSs include C-Si-Mn "Transformation-induced plasticity (TRIP) ${ }^{1)}$-aided bainitic ferrite (TBF)" steel and "Quench and Partitioning" (Q\&P) steel, which possess superior formability owing to TRIP of the metastable retained austenite. TBF steel is produced by an isothermal transformation (IT) process at temperatures higher than the martensite transformation-start temperature $\left(M_{\mathrm{s}}\right)$ (when the matrix structure is bainitic ferrite) or between $M_{\mathrm{s}}$ and the martensite transformation-finish temperature $\left(M_{\mathrm{f}}\right)$ temperature (when the matrix structure is a mixture of bainitic ferrite and martensite) after austenitizing. ${ }^{2,3)} \mathrm{Q} \& \mathrm{P}$ steel is fabricated by first quenching the steel at a temperature below $M_{\mathrm{s}}$ after austenitizing and then by partitioning $(\mathrm{P})$ at a temperature higher than $M_{\mathrm{s}}$ (the matrix structure is the same mixture of bainitic ferrite and martensite as in the case of TBF steel). ${ }^{4-6)}$

In order to increase the strength of TBF steel, Sugimoto et al. recently developed a $\mathrm{C}-\mathrm{Si}-\mathrm{Mn}$ "TRIP-aided martensitic" (TM) steel with a wide lath-martensite structure and a

\footnotetext{
* Corresponding author: E-mail: koba@sugimotolab.shinshu-u.ac.jp
} DOI: http://dx.doi.org/10.2355/isijinternational.54.1943 narrow lath-martensite/metastable austenite-retained complex phase (MA-like phase). ${ }^{7-10)}$ The TM steel was manufactured by the following two-step heat-treatment ITP process:

(1) IT process for $1000 \mathrm{~s}$ at temperatures below $M_{\mathrm{f}}$ after austenitizing.

(2) $\mathrm{P}$ process at temperatures between $200-350^{\circ} \mathrm{C}$ for $1000 \mathrm{~s}$ after the IT process, which further enriches the carbon concentration of the retained austenite.

The TM steel achieved superior stretch-flangeability as compared to TBF steel because of its unique microstructure. ${ }^{7)}$ By means of $\mathrm{Cr}, \mathrm{Mo}$, and Ni alloying, the microstructure and volume fraction of the retained austenite of the TM steel are respectively refined and increased. ${ }^{7)}$ The pressformability of the TM steel sheet is also expected to be improved by microalloying with $\mathrm{Cr}$, Mo, and $\mathrm{Ni}$; however, the effects of these alloying elements on the press-formability of TM steel have not yet been reported.

In the present study, the effects of $\mathrm{Cr}, \mathrm{Mo}$, and/or $\mathrm{Ni}$ alloying on the microstructure, retained austenite characteristics, tensile properties, stretch-formability, and stretchflangeability of TM steel subjected only to an IT process at temperatures below $M_{\mathrm{f}}$ were investigated in order to further improve the press-formability of TM steel. It was discovered that the tensile properties and stretch-flangeability were also related to some metallurgical factors. 


\section{Experimental Procedure}

Five kinds of steels with varying amounts of $\mathrm{Cr}$, Mo, and $\mathrm{Ni}$, listed in Table 1, were prepared in the form of $100 \mathrm{~kg}$ ingots by vacuum melting, which were then hot forged into slabs. The slabs were then heated to $1200^{\circ} \mathrm{C}$ and hot rolled into thin plates ( $3 \mathrm{~mm}$ in thickness) with a finishing rolling temperature of $850^{\circ} \mathrm{C}$, followed by cooling in air to room temperature and subsequent annealing at $650^{\circ} \mathrm{C}$. Finally, the plates were cold rolled to a thickness of $1.2 \mathrm{~mm}$ after acid pickling.

In general, the carbon equivalent $\left(C_{\mathrm{eq}}\right)$ is used in the evaluation of the hardenability of steels. Some commercial steel (e.g. $22 \mathrm{MnB} 5$ steel) contain boron at a concentration of $\sim 20$ ppm, along with the other alloying elements, for increasing hardenability; however, $C_{\text {eq }}$ does not include the effects of boron. Therefore, hardenability, defined as the product of the various Grossman pearlitic hardenability factors ${ }^{11)}$ $\left(\Pi f_{\mathrm{i}} \mathrm{s}\right)$, was used in this study. The value of $\Pi f_{\mathrm{i}}$ was calculated using the following equation:

$$
\begin{aligned}
\Pi f_{\mathrm{i}}=D_{\mathrm{I}} / D_{\mathrm{I}}^{*} & =(1+0.64 \% \mathrm{Si}) \times(1+4.1 \% \mathrm{Mn}) \times(1+2.83 \% \mathrm{P}) \\
& \times(1-0.62 \% \mathrm{~S}) \times(1+2.33 \% \mathrm{Cr}) \times(1+0.52 \% \mathrm{Ni}) \\
& \times(1+3.14 \% \mathrm{Mo}) \times(1+0.27 \% \mathrm{Cu}) \\
& \times(1+1.5(0.9-1.0 \% \mathrm{C})),
\end{aligned}
$$

where $D_{\mathrm{I}}$ and $D_{\mathrm{I}} *$ are the ideal critical diameters for the hardenability of alloyed and carbon steels, respectively. The effect of the prior austenite grain size is not considered in Eq. (1). The last term on the right-hand side of Eq. (1) is included only in the case of steel containing boron because the hardenability of boron-bearing steel is more sensitive to carbon content than to boron content. Hereafter, $\Pi f_{\mathrm{i}}$ is called the "hardenability factor" or "hardenability." The continuous cooling transformation (CCT) diagrams of steels A through $\mathrm{E}$ are shown in Fig. 1. $M_{\mathrm{s}}$ and $M_{\mathrm{f}}$ decrease with increasing hardenability factor (Fig. 2).

Tensile specimens with a gauge length of $50 \mathrm{~mm}$ and a gauge width of $12.5 \mathrm{~mm}$ and stretch-forming and hole-

\begin{tabular}{|c|c|c|c|c|c|c|c|c|}
\hline Steel & $\mathrm{C}$ & $\mathrm{Si}$ & $\mathrm{Mn}$ & $\mathrm{P}$ & $\mathrm{S}$ & $\mathrm{Al}$ & $\mathrm{Nb}$ & \\
\hline A & 0.20 & 1.50 & 1.50 & 0.0015 & 0.002 & 0.042 & 0.048 & \\
\hline B & 0.21 & 1.49 & 1.50 & 0.0019 & 0.004 & 0.040 & 0.050 & \\
\hline $\mathrm{C}$ & 0.20 & 1.49 & 1.50 & 0.0019 & 0.004 & 0.040 & 0.050 & \\
\hline $\mathrm{D}$ & 0.18 & 1.48 & 1.49 & 0.0029 & 0.004 & 0.043 & 0.050 & \\
\hline $\mathrm{E}$ & 0.21 & 1.49 & 1.49 & 0.0019 & 0.003 & 0.034 & 0.049 & \\
\hline Steel & $\mathrm{Cr}$ & Mo & $\mathrm{Ni}$ & $\mathrm{O}$ & $\mathrm{N}$ & $\mathrm{M}_{\mathrm{s}}$ & $\mathrm{M}_{\mathrm{f}}$ & $\Pi f_{\mathrm{i}}$ \\
\hline A & - & - & - & 0.0010 & 0.0012 & 409 & 289 & 14.6 \\
\hline B & 0.50 & - & - & 0.0012 & 0.0012 & 408 & 292 & 30.6 \\
\hline $\mathrm{C}$ & 1.00 & - & - & 0.0014 & 0.0012 & 406 & 261 & 47.0 \\
\hline $\mathrm{D}$ & 1.02 & 0.20 & - & 0.0015 & 0.0010 & 368 & 250 & 76.8 \\
\hline $\mathrm{E}$ & 1.00 & 0.20 & 1.52 & 0.0009 & 0.0014 & 357 & 245 & 135.8 \\
\hline
\end{tabular}

Table 1. Chemical composition (mass\%), measured martensitestart and -finish temperatures $\left(M_{\mathrm{s}}, M_{\mathrm{f}},{ }^{\circ} \mathrm{C}\right)$ and hardenability factor $\left(\Pi f_{i}\right)$ of steels used. expansion specimens $50 \mathrm{~mm}$ in length and width were machined from the cold-rolled steel sheets. These specimens were subjected to an IT process, as shown in Fig. 3. During cooling after austenitizing, $M_{\mathrm{s}}$ and $M_{\mathrm{f}}$ of the untransformed

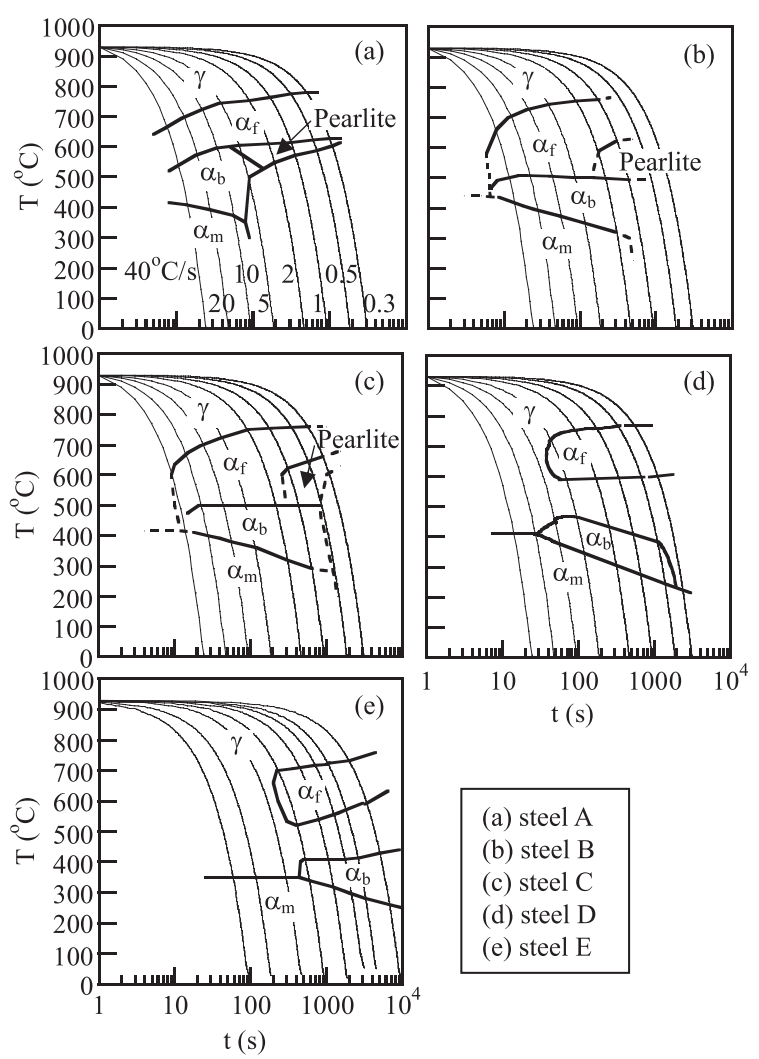

Fig. 1. Measured CCT diagrams of steels A through E, in which $\gamma$, $\alpha_{\mathrm{f}}, \alpha_{\mathrm{b}}$, and $\alpha_{\mathrm{m}}$ represent austenite, ferrite, bainite, and martensite, respectively.

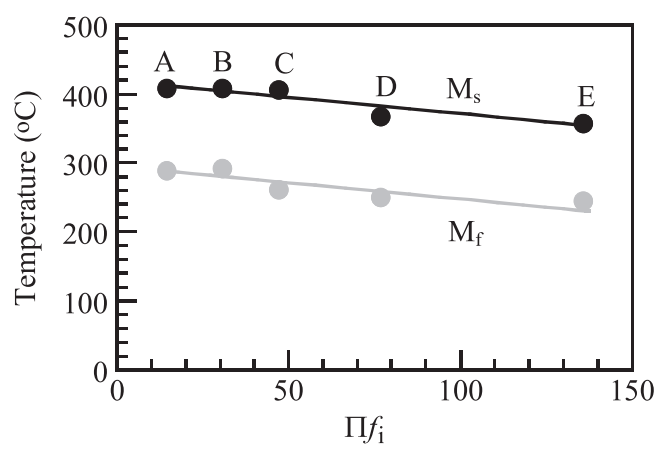

Fig. 2. Variations in martensite transformation-start $\left(M_{\mathrm{s}}\right)$ and -finish $\left(M_{\mathrm{f}}\right)$ temperatures as a function of hardenability factor $\left(\Pi f_{\mathrm{i}}\right)$ in steels A through E.

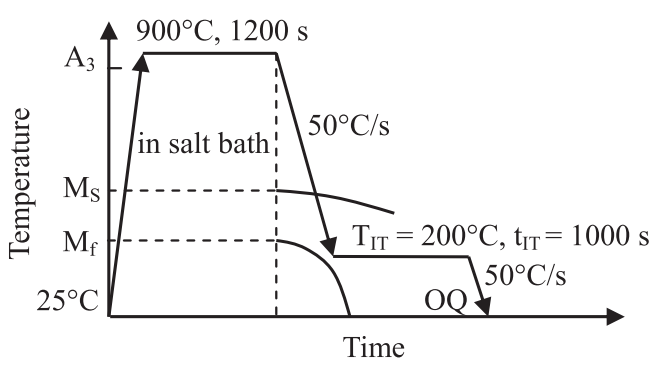

Fig. 3. Heat treatment diagram of IT process, in which OQ represents quenching in oil. 
austenite may decrease owing to carbon partitioning from martensite. Similar to previous studies, ${ }^{6-8)}$ the austenitizing was performed at $900^{\circ} \mathrm{C}$ for $1200 \mathrm{~s}$ and then the IT process was performed at $200^{\circ} \mathrm{C}$ for $1000 \mathrm{~s}$.

The microstructure of the steels was examined by transmission electron microscopy (TEM; JEM-2010, JEOL Ltd.) and electron backscatter diffraction pattern (EBSP) analysis using field emission scanning electron microscopy (FESEM; JSM-6500F, JEOL Ltd.). The volume fraction of carbide in the specimens was measured as follows. First the specimens were etched in a 5\% nital etchant and then a carbon film was coated on the specimen. The carbon replicas with carbides were then peeled off the specimens in an ethanol solution containing 30\% nitric acid, followed by TEM examination and image analysis in an area of approximately $560 \mu \mathrm{m}^{2}$.

The characteristics of the retained austenite in the steels were quantified by X-ray diffraction (XRD; RINT2100, Rigaku Co.). Specimens were electropolished after being ground with emery paper (\#2000). As described by Maruyama, ${ }^{12)}$ the volume fraction of the retained austenite $\left(f_{\gamma}, \mathrm{vol} \%\right)$ was calculated from the integration of the intensities of the $(200)_{\alpha},(211)_{\alpha},(200)_{\gamma},(220)_{\gamma}$, and $(311)_{\gamma}$ peaks from the XRD studies performed using Mo K $\alpha$ radiation. The carbon concentration $\left(\mathrm{C}_{\gamma}\right.$, mass $\left.\%\right)$ was estimated by substituting the lattice constant ( $a_{\gamma}$, units of $\left.10^{-1} \mathrm{~nm}\right)$ measured from the $(200)_{\gamma},(220)_{\gamma}$, and (311) $\gamma$ peaks of $\mathrm{Cu} \mathrm{K} \alpha$ radiation into the following equation proposed by Dyson and Holmes: ${ }^{13)}$

$$
\begin{aligned}
a_{\gamma} & =3.5780+0.0330 \% \mathrm{C}_{\gamma}+0.00095 \% \mathrm{Mn}_{\gamma} \\
& -0.0002 \% \mathrm{Ni}_{\gamma}+0.0006 \% \mathrm{Cr}_{\gamma}+0.0220 \% \mathrm{~N}_{\gamma} \\
& +0.0056 \% \mathrm{Al}_{\gamma}-0.0004 \% \mathrm{Co}_{\gamma}+0.0015 \% \mathrm{Cu}_{\gamma} \\
& +0.0031 \% \mathrm{Mo}_{\gamma}+0.0051 \% \mathrm{Nb}_{\gamma}+0.0039 \% \mathrm{Ti}_{\gamma} \\
& +0.0018 \% \mathrm{~V}_{\gamma}+0.0018 \% \mathrm{~W}_{\gamma},
\end{aligned}
$$

where $\% \mathrm{Mn}_{\gamma}, \% \mathrm{Ni}_{\gamma}, \% \mathrm{Cr}_{\gamma}, \% \mathrm{~N}_{\gamma}, \% \mathrm{Al}_{\gamma}, \% \mathrm{Co}_{\gamma}, \% \mathrm{Cu}_{\gamma}, \% \mathrm{Mo}_{\gamma}$, $\% \mathrm{Nb}_{\gamma}, \% \mathrm{Ti}_{\gamma}, \% \mathrm{~V}_{\gamma}$, and $\% \mathrm{~W}_{\gamma}$ represent the concentrations of the respective individual elements (mass\%) in the retained austenite phase. For convenience, the amounts of the added alloying elements were substituted for these concentrations in this study.
Tensile tests were carried out on a hard type of testing machine. The strain rate was $3.3 \times 10^{-3} \mathrm{~s}^{-1}$ and the tensile direction was parallel to the rolling direction of the sheet. In order to investigate the initial yield behavior, a strain gauge was attached to the gauge section of the specimen. The holepunching and hole-expanding tests were conducted with a graphite-type lubricant. First, a hole $4.76 \mathrm{~mm}$ in diameter was punched out at a punching rate of $10 \mathrm{~mm} / \mathrm{min}$, with a clearance of $10 \%$ between the die and the punch. The successive hole-expansion tests were performed at a punching rate of $1 \mathrm{~mm} / \mathrm{min}$. In the expansion tests, the punch was in contact with the roll-over section of the hole-punched specimens. The hole-expansion ratio $(\lambda)$ was determined by the following equation:

$$
\lambda=\left[\left(d_{\mathrm{f}}-d_{0}\right) / d_{0}\right] \times 100 \%,
$$

where $d_{0}$ and $d_{\mathrm{f}}$ are the initial hole diameter and the hole diameter upon cracking, respectively. Stretch-forming tests were also performed to measure the maximum stretch height, $H_{\max }$, without cracking. The punching rate was 1 $\mathrm{mm} / \mathrm{min}$ and a cylindrical punch with a diameter of $17.4 \mathrm{~mm}$ and a curvature radius of $8.7 \mathrm{~mm}$ was used. ${ }^{10)}$ The forming tests were carried out twice in this study. The error margins in the hole-expanding ratio and maximum stretch height were $1-3 \%$ and $0.05-0.2 \mathrm{~mm}$, respectively. All tests were conducted at $25^{\circ} \mathrm{C}$.

\section{Results}

\subsection{Microstructure and Retained Austenite Character- istics}

Figure 4 shows SEM images of the microstructure of steels A through E. The results from EBSP analysis of steels $A$ and $D$ are shown in Fig. 5. Based on these results, the body-centered cubic (Fe- $\alpha$, bcc) structures of the TM steel consisted of high image quality (IQ) index and low IQ index structures. According to Kobayashi et al., ${ }^{3)}$ the martensitic and bainitic ferrite matrices possess a high IQ index, whereas the MA phase in TBF steel possesses a low IQ index. Thus, the high IQ index structure in Fig. 4 seems to be a soft, wide lath-martensite structure with a low dislocation density. ${ }^{14)}$ This wide lath-martensite structure was auto-tempered during cooling after austenitizing. The width of the lath-martensite

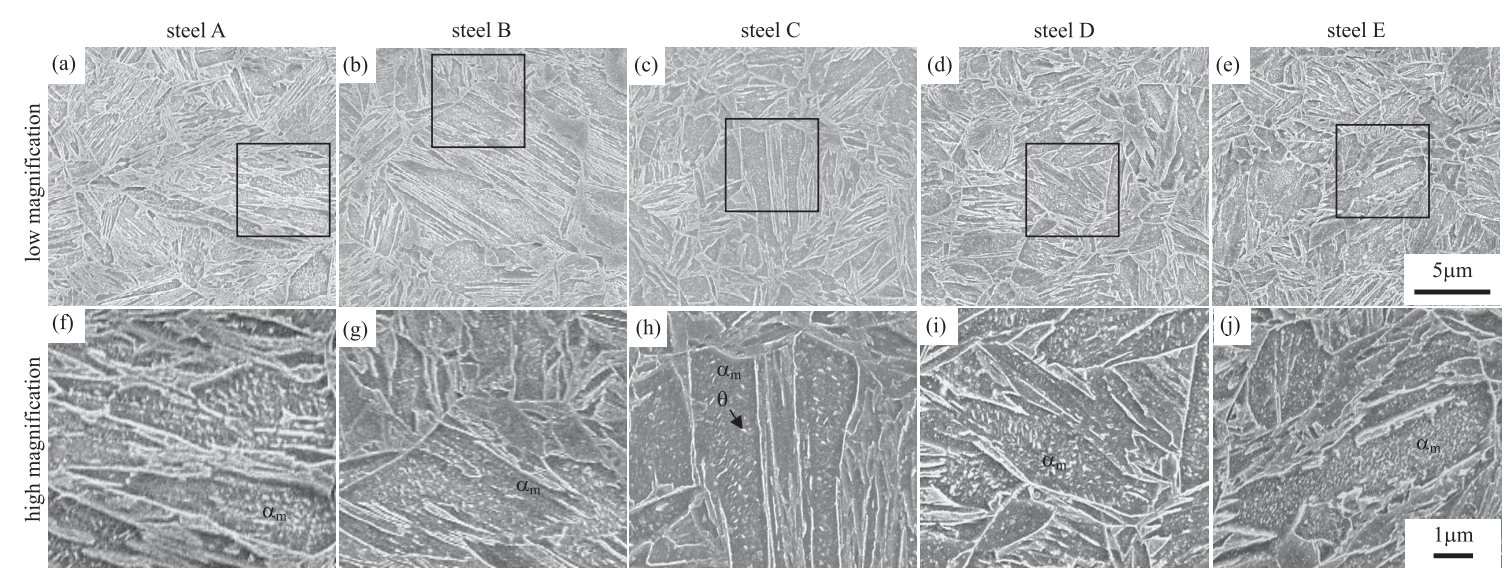

Fig. 4. SEM images of steels A through $\mathrm{E}$, in which $\alpha_{\mathrm{m}}$ and $\theta$ represent wide lath-martensite and carbide, respectively. Bottom images are responsible to square region in upper images. 

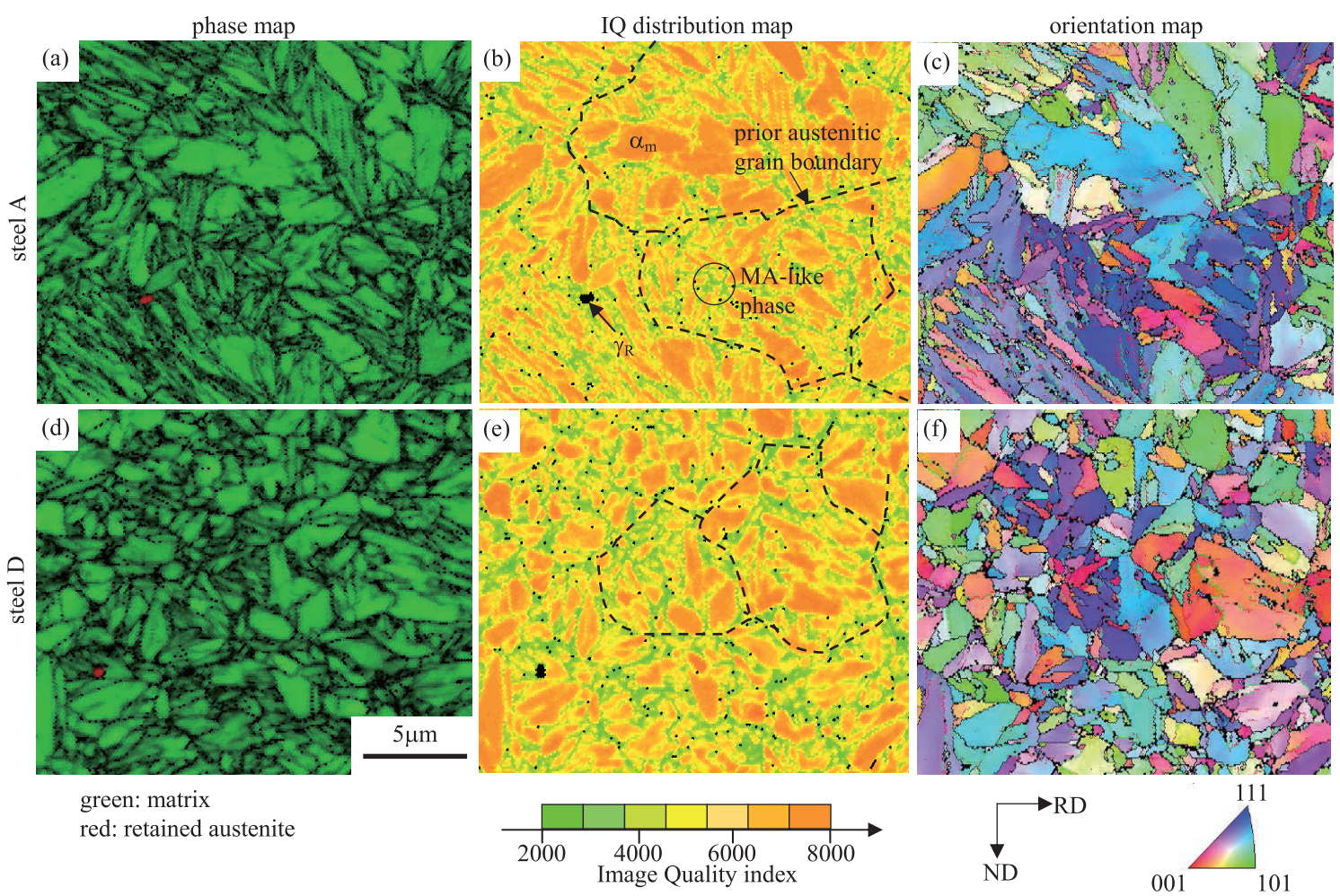

Fig. 5. Phase maps and image quality (IQ) distribution and orientation maps of Fe- $\alpha$ (bcc) in steels A and D, in which $\alpha_{\mathrm{m}}$ and $\gamma_{R}$ represent wide lath-martensite and retained austenite, respectively.
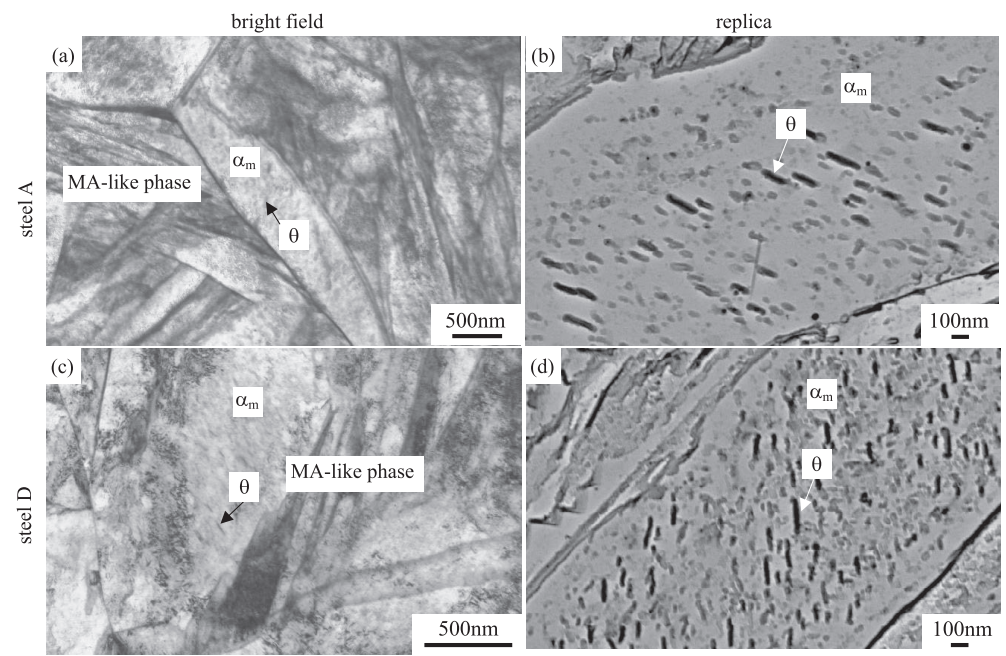

Fig. 6. TEM images of bright field and replica of steels $\mathrm{A}$ and $\mathrm{D}$, in which $\alpha_{\mathrm{m}}$ and $\theta$ represent wide lath-martensite and carbide, respectively.

was $0.5-1.0 \mu \mathrm{m}$. As shown in Figs. 4(f)-4(j), needle-like carbides were observed in the wide lath-martensite structures. The low IQ index structure was a blocky phase composed of fine lath-martensite and retained austenite. The blocky secondary phase appears to be a martensite-austenite constituent or phase, which was observed in martensitic steel in a previous study. ${ }^{15)}$ Hereafter, the blocky secondary phase is referred to as an "MA-like phase." The MA-like phase was primarily located on the prior austenite grains, packets, and martensite block boundaries. The fraction of the MA-like phase increased with increasing hardenability. In addition, these MA-like phases were also finely dispersed with increasing hardenability (Figs. 5(b) and 5(e)).

TEM images of steels A (base steel) and D (Cr-Mo-bearing steel) are shown in Fig. 6. In this figure, the blocky secondary phase was found to possess a narrow lath-martensite structure $\left(\alpha_{\mathrm{m}}{ }^{*}\right)$ with a high dislocation density. Considering the IQ map distribution of Figs. 5(b) and 5(e), the retained austenite appears to be located on a narrow lath-martensite boundary. Carbides in Figs. 4 and 6, which were precipitated only in wide lath-martensite, were detected to be cementite $\left(\mathrm{Fe}_{3} \mathrm{C}\right)$. The length of the carbide was approximately $200 \mathrm{~nm}$. The sizes of the carbides in steels B through D were slightly smaller than that of steel A. These carbides were precipitated by auto-tempering during cooling after austenitizing.

Figure 7 shows the initial volume fraction and carbon concentration of the retained austenite, the volume fractions of the MA-like phase and carbide, and the stability of the 


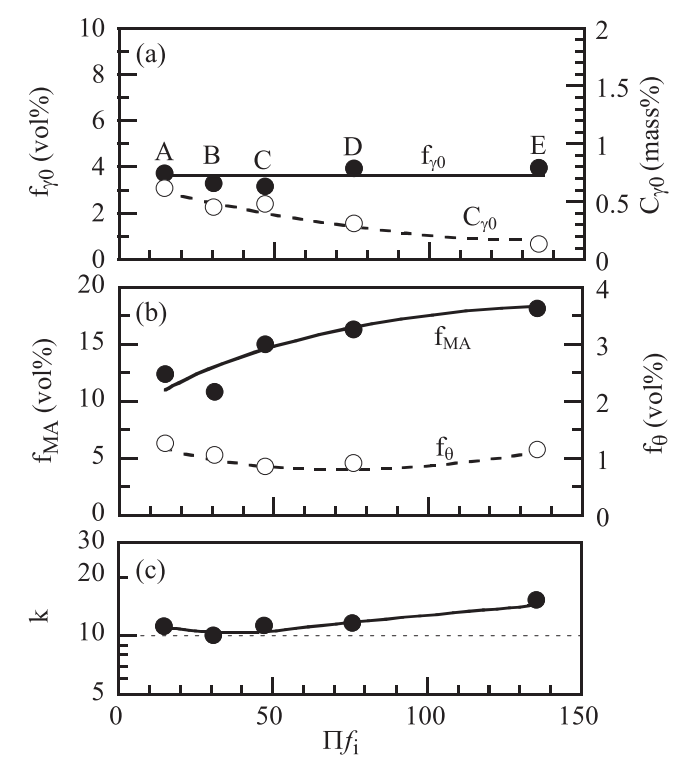

Fig. 7. Variations in (a) initial volume fraction $\left(f_{\gamma 0}\right)$ and carbon concentration $\left(C_{\gamma 0}\right)$ of retained austenite, (b) volume fractions of MA-like phase $\left(f_{\mathrm{MA}}\right)$ and carbide $\left(f_{\theta}\right)$ and (c) straininduced transformation factor $(k)$ as a function of hardenability factor $\left(\Pi f_{\mathrm{i}}\right)$ in steels A through $\mathrm{E}$.

retained austenite against the strain-induced martensite transformation $(k)$ value as a function of hardenability factor in steels A through $\mathrm{E}$. The $k$ value was calculated by the following equation: ${ }^{16)}$

$$
\log f_{\gamma}=\log f_{\gamma 0}-k \varepsilon,
$$

where $f_{\gamma}$ is the volume fraction of the retained austenite after applying plastic strain, $\varepsilon$, and $f_{\gamma 0}$ is the original volume fraction of the retained austenite. In Fig. 7(a), the initial volume fraction of the retained austenite had only a slight dependence on the hardenability factor. On the other hand, the initial carbon concentration of the retained austenite clearly decreased with increasing hardenability. Although the $k$ value of steel E (Cr-Mo-Ni-bearing steel) slightly increased (i.e., the retained austenite became unstable), the hardenability dependence of the $k$ value was small (Fig. 7(c)).

The carbide fraction in steels A through $\mathrm{E}$ was between 0.8 and $1.2 \mathrm{vol} \%$, and it minimally depended on the hardenability (Fig. 7(b)). The volume fractions of the MA-like phase in steels A through E were 11-18 vol\% and the fractions increased with increasing hardenability.

\subsection{Tensile Properties}

Figure 8 shows the engineering stress-strain curves of steels A, C, and D. The tensile properties of steels A through $\mathrm{E}$ are shown in Fig. 9. The tensile strengths of steels $\mathrm{A}$ through E were of an ultrahigh strength grade, at 1.5 GPa. The tensile strength, yield stress (or $0.2 \%$ offset proof stress), and yield ratio of steels A through E increased with increasing hardenability (Figs. 9(a) and 9(b)). In particular, the yield stress and yield ratio were significantly dependent on hardenability.

The uniform, local, and total elongations and a combination of the tensile strength and total elongation were hardly changed with increasing hardenability (Fig. 9(c)). The reductions of area in steels $\mathrm{D}$ and $\mathrm{E}$ were lower than those of steels A, B, and C (Fig. 9(d)).
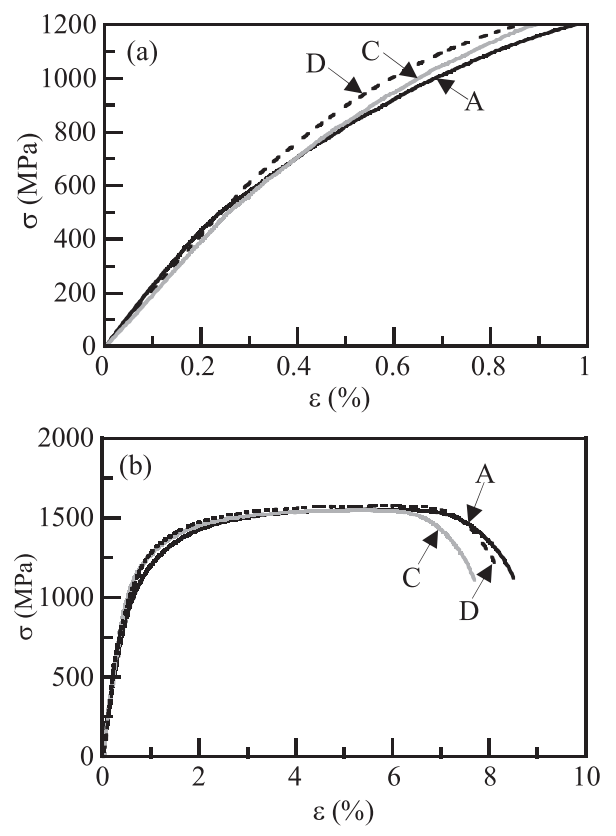

Fig. 8. Typical engineering stress $(\sigma)$ - strain $(\varepsilon)$ curves of steels A, $\mathrm{C}$, and $\mathrm{D}$. (a) is $\sigma-\varepsilon$ curves in early stage of (b).
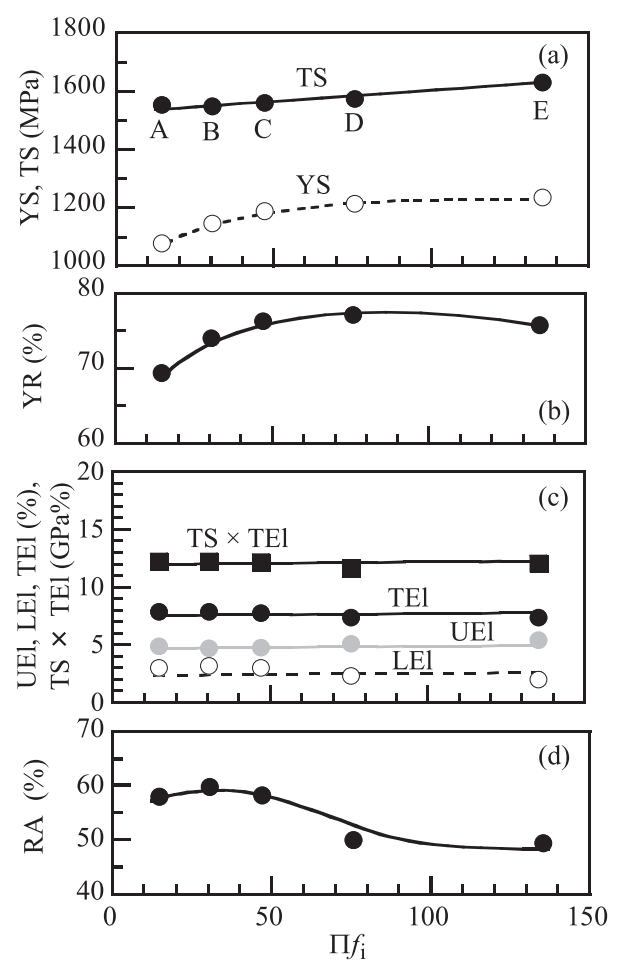

Fig. 9. Variations in (a) yield stress or $0.2 \%$ offset proof stress $(Y S)$ and tensile strength $(T S)$, (b) yield ratio $(Y R=Y S / T S)$, (c) uniform $(U E l)$, local $(L E l)$, and total $(T E l)$ elongations and combination of tensile strength and total elongation $(T S \times$ $T E l$ ) and (d) reduction of area $(R A)$ as a function of hardenability factor $\left(\Pi f_{\mathrm{i}}\right)$ in steels A through $\mathrm{E}$.

\subsection{Stretch-flangeability and Stretch-formability}

The hole-expanding ratio, a combination of tensile strength and hole-expanding ratio, maximum stretch height, and a combination of tensile strength and maximum stretch height in steels $\mathrm{A}$ through $\mathrm{E}$ as a function of hardenability are shown in Fig. 10. The hole-expanding ratio of steel A was $28.4 \%$. The hole-expanding ratios of steels $\mathrm{B}$ and $\mathrm{C}(\mathrm{Cr}-$ 
bearing steels) increased respectively to $35.7 \%$ and $38.3 \%$, which were approximately $10 \%$ higher than that of steel A. On the other hand, the hole-expanding ratios of steels $\mathrm{D}$ and E were roughly equal to that of steel $A$. The combination of tensile strength and hole-expanding ratio of steel $\mathrm{C}$ was the

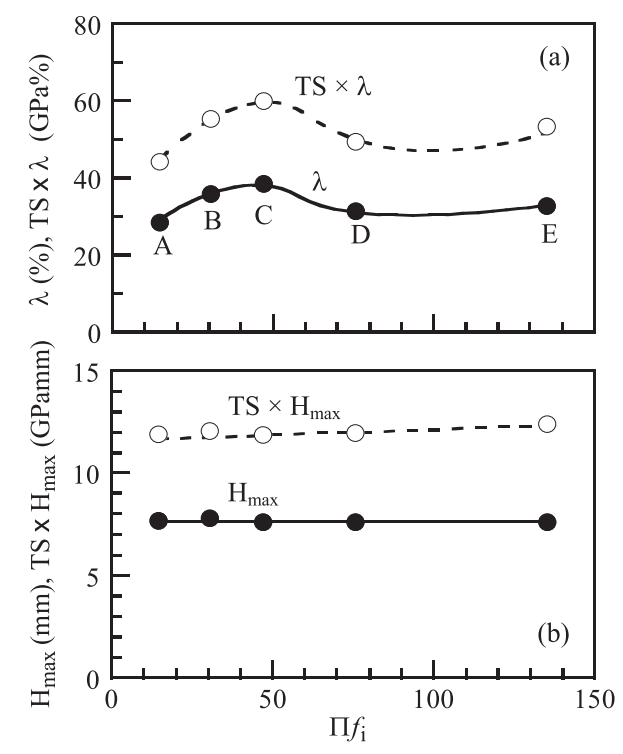

Fig. 10. Variations in (a) hole-expanding ratio $(\lambda)$ and combination of tensile strength and hole-expanding ratio $(T S \times \lambda)$ and (b) maximum stretch-height $\left(H_{\max }\right)$ and combination of tensile strength and maximum stretch-height (TS $\times$ $\left.H_{\max }\right)$ as a function of hardenability factor $\left(\Pi f_{\mathrm{i}}\right)$ in steels A through E.

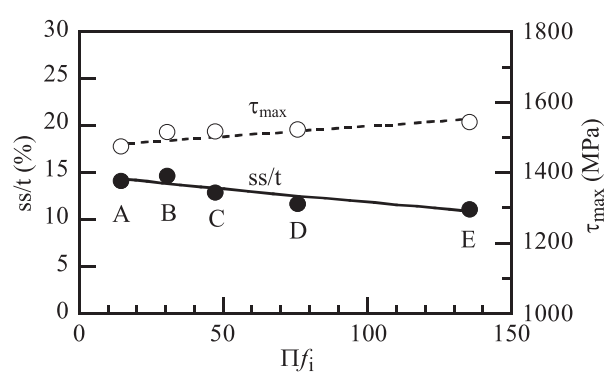

Fig. 11. Variations in ratio of shear section length to sheet thickness $(s s / t)$ and punching shear stress $\left(\tau_{\max }\right)$ as a function of hardenability factor $\left(\Pi f_{\mathrm{i}}\right)$ in steels A through E. highest of all the steels. Although the hole-expanding ratio and combination of tensile strength and hole-expanding ratio changed with changing hardenability factor, the maximum stretch height and combination of tensile strength and maximum stretch height in steels A through E were nearly constant.

Figure 11 shows the ratio of shear section length to sheet thickness and punching shear stress as a function of hardenability factor. The ratio of shear section length to sheet thickness decreased with increasing hardenability. In contrast, the punching shear stresses of the steels increased with increasing hardenability.

SEM images of the break section of the hole-surface pierced by punch in steels A, C, and D are shown in Fig. 12. Dimple fractures appeared on the fracture surface of steels A through E. The dimple size on the fracture surface decreased with increasing hardenability (Figs. 12(a)-12(c)). In cross-sectional images of Figs. 12(d)-12(f), a smaller number of fine voids and cracks seemed to be observed in steel $\mathrm{C}$ as compared with steels $\mathrm{A}$ and $\mathrm{D}$. The voids appear to be formed at the wide lath-martensite structure matrix/ MA-like phase interface.

\section{Discussion}

\subsection{Microstructure Formation and Carbon Enrichment into Retained Austenite in TM Steel with High Hardenability}

The microstructure of steels B through E consisted of a fine, uniform, wide lath-martensite structure matrix and an MA-like phase (Fig. 5). The volume fractions of the MAlike phase increased with the addition of $\mathrm{Cr}, \mathrm{Mo}$, and/or Ni (Fig. 7(b)). On the other hand, the volume fractions of the retained austenite in steels $\mathrm{B}$ and $\mathrm{C}$ (Cr-bearing steels) were the smallest of all the steels, although the carbon concentration of the retained austenite in steels A through E decreased with increasing hardenability factor (Fig. 7(a)). In order to investigate the change in these retained austenite characteristics, the dilatometry curves of steels A through E were plotted. The typical dilatometer curves and martensite transformation fractions of steels $\mathrm{A}$ and $\mathrm{D}$ as a function of temperature are shown in Figs. 13(a) and 13(b), respectively. The martensite transformation fraction resulting from the

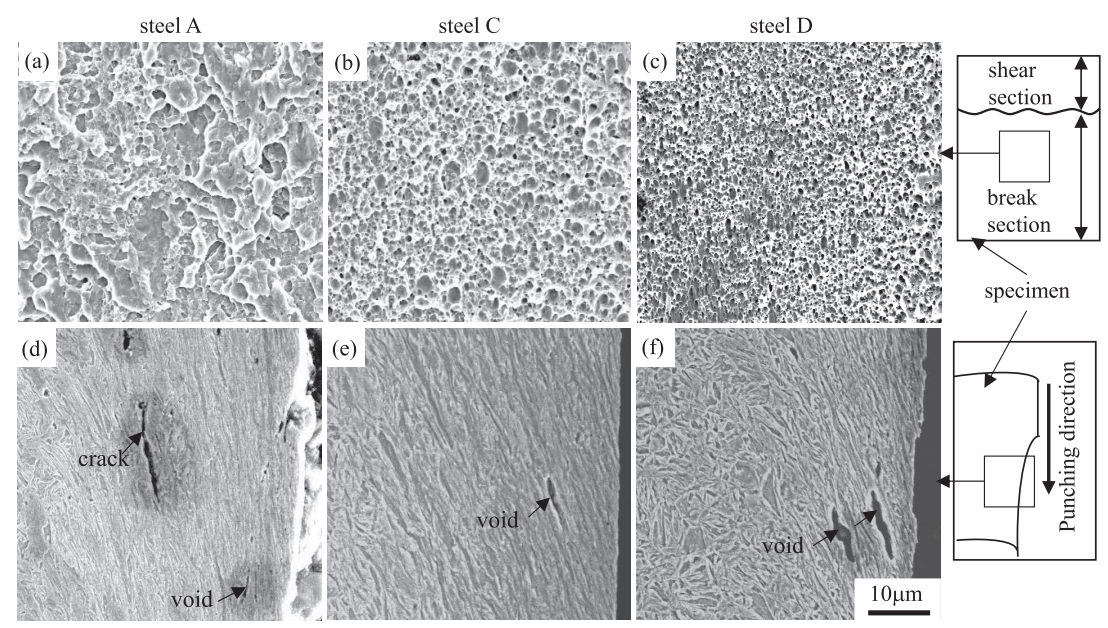

Fig. 12. SEM images of break section of hole-surface pierced by punch in steels (a, d) A, (b, e) C, and (c, f) D. 
dilatometer was fitted using the volume fraction of each phase as determined from SEM observation, EBSP, and Xray diffraction analyses. In Fig. 13, the martensitic transformation of steel D shifted to a lower temperature as compared to steel A.

Based on Figs. 5-7, and 13(b), the microstructural changes of steels B through E are schematically illustrated in Fig.
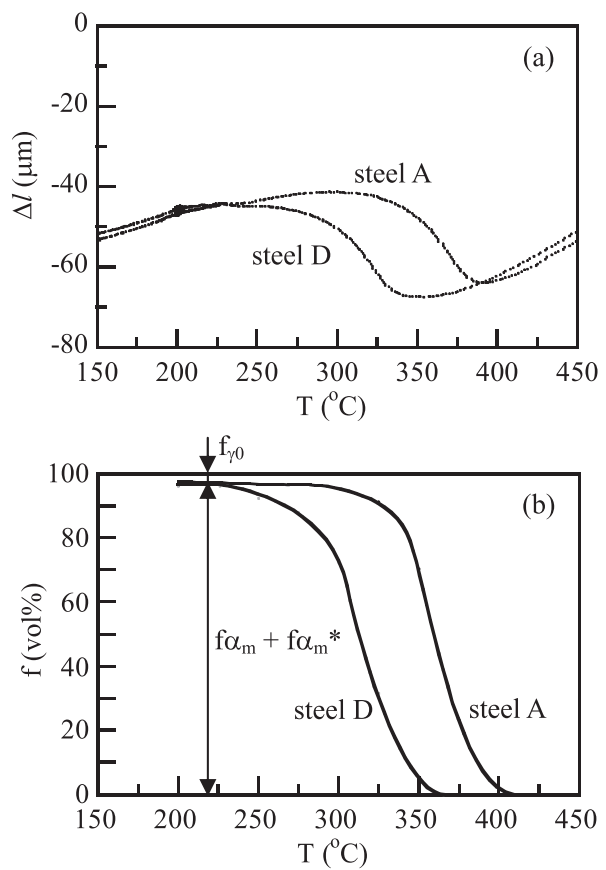

Fig. 13. Typical (a) dilatometer $(\Delta l)$ - temperature $(T)$ curves and (b) martensite transformation fraction $\left(f \alpha_{\mathrm{m}}+f \alpha_{\mathrm{m}}{ }^{*}\right)$ - temperature $(T)$ curves of steels $\mathrm{A}$ and $\mathrm{D}$, in which $f \alpha_{\mathrm{m}}, f \alpha_{\mathrm{m}}{ }^{*}$, and $f_{\gamma 0}$ represent volume fractions of wide lath-martensite, narrow lath-martensite, and initial retained austenite, respectively.
14. First, we will discuss the mechanism of the microstructural formation in steel A. According to Kobayashi et al., ${ }^{8)}$ the microstructure of steel A changed as follows:

Stage 1: The microstructure was originally austenite.

Stages 2-3: When the steel was quenched to temperature $T_{3}$, which is lower than $M_{\mathrm{s}}$, a large amount of the austenite phase transformed to wide lath-martensite $\left(\alpha_{\mathrm{m}}\right)$. The untransformed austenite was located on the prior austenitic grains, packets, and block boundaries. In this situation, the volume fraction of the wide lath-martensite $\left(f \alpha_{\mathrm{m}}\right)$ increased with decreasing quenching temperature according to the following equation reported by Koistinen and Marburger: ${ }^{17)}$

$$
f \alpha_{m}=1-\exp \left[-1.1 \times 10^{-2}\left(M_{\mathrm{s}}-T_{3}\right)\right],
$$

where $T_{3}$ is an arbitrary temperature during cooling below $M_{\mathrm{s}}$. Namely, the wide lath-martensite fraction increases with increasing $M_{\mathrm{s}}$ because $\left(M_{\mathrm{s}}-T_{3}\right)$ increases.

Stages 3-4: Carbide precipitated only in the wide lathmartensite with supersaturated carbon by auto-tempering during cooling. At the same time, the carbon in the martensite partitioned to untransformed austenite. If the steel was cooled to near $M_{\mathrm{f}}$, then most of the untransformed austenite transformed to narrow lath-martensite, and a small amount of untransformed austenite was retained. This complex phase was confirmed to be the MA-like phase. The retained austenite was mainly located on the narrow lath-martensite boundaries. Carbides did not precipitate in the narrow lathmartensite since auto-tempering was suppressed by the lowered $M_{\mathrm{s}}$ temperature, resulting in the increased carbon concentration of untransformed austenite.

Stages 4-6: Supersaturated carbon in wide and narrow lath-martensite further partitioned into untransformed austenite during the IT process. As a result, the carbon concentration of untransformed austenite increased. From the results of TEM observation, the size and volume fraction of
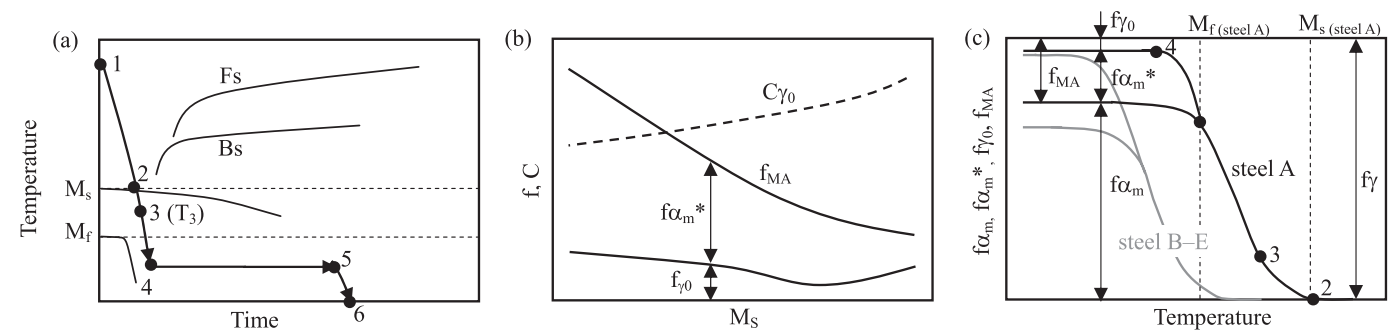

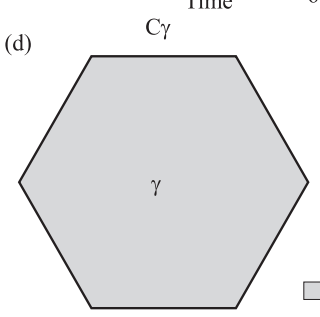

stage 1

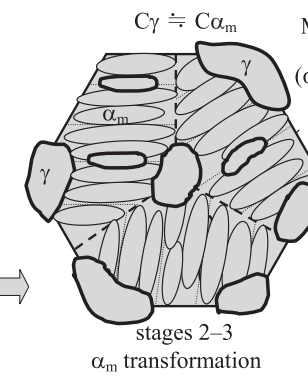
MA-like $\quad \mathrm{C} \alpha_{\mathrm{m}}<\mathrm{C} \gamma \doteqdot \mathrm{C} \alpha_{\mathrm{m}}{ }^{*}$ MA-like phase Temperature

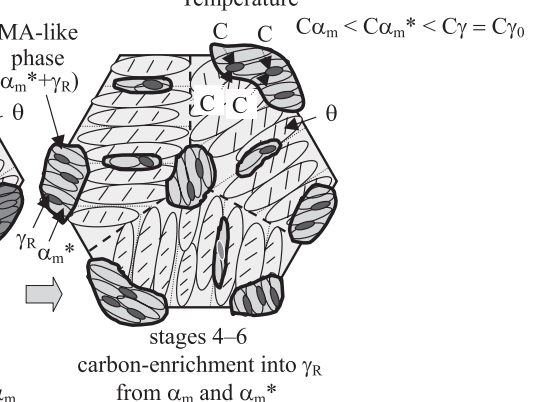

$\alpha_{\text {a }}$-mpering of $\alpha_{\mathrm{m}}$ carbon-enrichment into $\gamma$ from $\alpha_{\mathrm{m}}$ $\alpha_{\mathrm{m}}{ }^{*}$ transformation of $\gamma$

Fig. 14. Illustration of (a) heat treatment diagram, (b) martensite-start temperature $\left(M_{\mathrm{S}}\right)$ dependences of initial volume fraction $\left(f_{\gamma 0}\right)$ and carbon concentration $\left(C_{\gamma 0}\right)$ of retained austenite and volume fractions of MA-like phase $\left(f_{\mathrm{MA}}\right)$ and narrow lath-martensite $\left(f \alpha_{\mathrm{m}}{ }^{*}\right),(\mathrm{c})$ variation in volume fraction of wide lath-martensite $\left(f \alpha_{\mathrm{m}}\right), f \alpha_{\mathrm{m}}{ }^{*}, f_{\mathrm{MA}}$, and $f_{\gamma 0}$ with temperature and (d) microstructural change at stages 1 through 6 during heat treatment in steel D, in which $\alpha_{\mathrm{m}}, \alpha_{\mathrm{m}}{ }^{*}, \gamma, \gamma_{\mathrm{R}}, \theta$, MA, and C represent wide lath-martensite, narrow lath-martensite, austenite, retained austenite, carbide, MA-like phase, and solute carbon, respectively. $\mathrm{C}_{\gamma}, \mathrm{C} \alpha_{\mathrm{m}}$, and $\mathrm{C} \alpha_{\mathrm{m}}{ }^{*}$ are carbon concentrations of austenite, wide lath-martensite, and narrow lath-martensite, respectively. 
carbide in the wide lath-martensite were only slightly affected by the IT process in this study.

In this study, the microstructural changes of steels B through E were nearly the same as that of steel A (Figs. 46 ), although the carbon concentration of the retained austenite decreased and the volume fraction of the MA-like phase increased with increasing hardenability in steels B through E (Figs. 7(a) and 7(b)). The reason why the carbon concentration of the retained austenite decreased with increasing hardenability factor can be considered as follows: the volume fractions of untransformed austenite at stages 3-4 in steels B through $\mathrm{E}$ increased with the decrease in $M_{\mathrm{s}}$, as shown in Fig. 14(c). Thus, carbon partitioning to the untransformed austenite from wide lath-martensite was somewhat decreased owing to an increase in the volume fractions of the untransformed austenite or to a decrease in the difference in the carbon concentration between wide-lath martensite and untransformed austenite. In steels B through $\mathrm{E}$, the above decrease in $M_{\mathrm{s}}$ may also lead to the refining of the martensite block structure and suppression of carbide precipitation.

\subsection{The Increase of Yield Stress and Yield Ratio with Alloying}

In Fig. 9, the yield stress and yield ratio of steels B through E increased as compared to steel A. According to the initial yield model of Sakaki et al. ${ }^{18)}$ and Sugimoto et $a l .,{ }^{19)}$ the elastic limit $Y_{\mathrm{e}}{ }^{18)}$ and strain hardening increment $\Delta \sigma^{19)}$ in a dual-phase steel containing a martensite secondary phase are estimated by the following equations (see Fig. 15):

$$
\begin{array}{r}
Y_{\mathrm{e}}=Y\left\{-1 / 2 \times\left(Y_{0} / Y\right)+\left[1-3 / 4 \times\left(Y_{0} / Y\right)^{2}\right]^{1 / 2}\right\} \\
\Delta \sigma=f_{\mathrm{S}} K E \varepsilon_{0}, \ldots \ldots \ldots \ldots \ldots \ldots \ldots \ldots \ldots \ldots \ldots \ldots \ldots \ldots \ldots \ldots \ldots \ldots
\end{array}
$$

where $Y$ and $Y_{0}$ are the yield strengths of the soft matrix structure at room temperature and upon the martensitic transformation of untransformed austenite, respectively (in this case, $Y>Y_{0}$ ). The symbols $f_{\mathrm{S}}, K, E$, and $\varepsilon_{0}$ are the volume fraction, morphological coefficient of the secondary phase, Young's modulus of the matrix and secondary phase, and plastic strain in the matrix, respectively. In this case, it was assumed that the secondary phase deformed elastically. In the present study, the $f_{\mathrm{S}}$ and soft matrix structure can be replaced by the volume fraction of the MA-like phase, $f_{\mathrm{MA}}$, and wide lath-martensite matrix structure. If $Y_{0} / Y$ is approx-

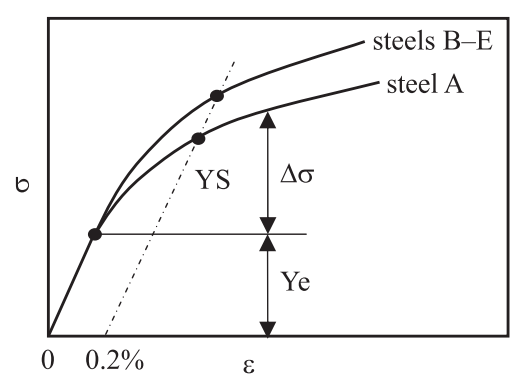

Fig. 15. Illustration of stress $(\sigma)$ - strain $(\varepsilon)$ curves in early stage and definition of elastic limit $\left(Y_{\mathrm{e}}\right), 0.2 \%$ offset proof stress $(Y S)$ and strain hardening increment $(\Delta \sigma)$ in steel A and steels B through E. imately $0.8, Y_{\mathrm{e}}$ is $0.32 Y$. Thus, the lower yield strength of steel A may have been caused by a low elastic limit at initial yielding. Although the elastic limits of steels B through $\mathrm{E}$ may be equal to that of steel A, their strain-hardening increments are higher than that of steel A because of an increase in the volume fractions of the MA-like phase in steels B through E. From a microstructural perspective, although the volume fraction of carbide in steel $\mathrm{C}$ was slightly lower than that of steel A, the volume fraction of the MA-like phase increased (Fig. 7(b)). In addition, the martensite block and lath structures of steels B through $\mathrm{E}$ were refined in keeping with the decrease in $M_{\mathrm{s}}$ and the finely dispersed MA-like phase. In spite of the decrease in carbon concentration of the retained austenite in steels $\mathrm{B}$ through $\mathrm{E}$, the stabilities of the retained austenite against strain were equal to that of steel A (Fig. 7(c)). Therefore, the higher yield strengths of steels $\mathrm{B}$ through $\mathrm{E}$ are caused by a larger hardening increment flow stress with increasing volume fraction of the MA-like phase in a strain range from the elastic limit to $0.2 \%$ strain (Fig. 15) and the fine martensite block and lath structures. The high-yield ratios of steels B through E may be caused by relatively high yield stress as compared to tensile strength.

\subsection{Effects of Alloying Elements on Stretch-flangeability}

The best combination of tensile strength and stretchflangeability was achieved by adding $0.5 \% \mathrm{Cr}$ and $1.0 \% \mathrm{Cr}$ (Fig. 10(a)). According to Sugimoto et al., ${ }^{16)}$ the stretchflangeability of TRIP-aided steel with a lath-type structure matrix is mainly controlled by the punching damage in the hole-surface layer and the localized ductility upon expansion. The punching damage is controlled by the following metallurgical factors:

(1) Matrix: Fine and uniform packet, block, and lath structures suppress void and crack initiation.

(2) Secondary phase: A small difference of flow stress between the matrix and the secondary phase and the low secondary-phase fraction suppress void and crack initiation at the matrix/secondary-phase interface.

(3) Retained austenite: A larger amount and higher stability of the retained austenite suppresses crack initiation through the plastic relaxation of localized stress concentration resulting from the strain-induced transformation to martensite.

(4) Carbide: Carbides located on prior austenitic grains, packet, blocks, and lath boundaries play a role in crack nucleation sites. If the carbide size in wide lathmartensite structure is relatively large, voids and cracks initiate near the carbide.

In the present study, the retained austenite characteristics and the volume fraction of carbide in steels A through $\mathrm{E}$ changed minimally (Fig. 7). On the other hand, the volume fraction of the MA-like phase increased and the MA-like phase was finely dispersed (by decreasing the size of the martensite block) with increasing hardenability factor. The hardenability dependence of metallurgical properties and the stretch-flangeability are illustrated in Fig. 16. Based on roles (1)-(4) described above and Fig. 16, the highest stretch-flangeability of steels $\mathrm{B}$ and $\mathrm{C}$ can be explained as follows.

If the volume fraction of the MA-like phase increases, 

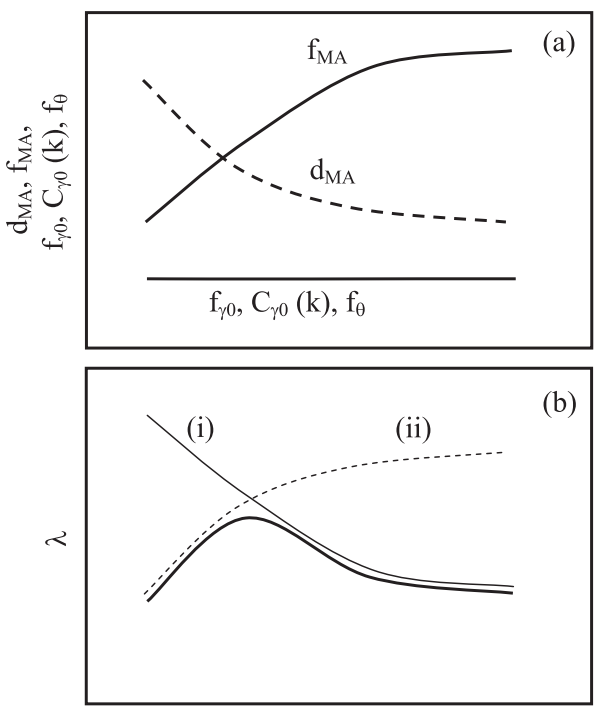

$\Pi f i$

Fig. 16. Illustrations of variations in (a) volume fraction $\left(f_{\mathrm{MA}}\right)$ and interparticle path $\left(d_{\mathrm{MA}}\right)$ of MA-like phase, retained austenite characteristics $\left(f_{\gamma 0}, C_{\gamma 0}(k)\right)$ and carbide fraction $\left(f_{\theta}\right)$ and (b) stretch-flangeability $(\lambda)$ as a function of hardenability factor $\left(\Pi f_{\mathrm{i}}\right)$. In (b), line (i) decreases stretch-flangeability due to increasing of $f_{\mathrm{MA}}$, and line (ii) increases stretchflangeability due to decreasing of $d_{\text {MA }}$.

stretch-flangeability is reduced by easy void initiation at the matrix/MA-like phase interface, as line (i) in Fig. 16(b) shows. In contrast, the stretch-flangeability is increased by the fine microstructure resulting from the short interparticle path of the MA-like phase $\left(d_{\mathrm{MA}}\right)$, as line (ii) in Fig. 16(b). According to the McClintock model for the coalescence of voids, ${ }^{20,21)}$ which consists of cylindrical holes with an average distance between the holes, the strain to fracture possesses a proportional relation to the distance. In the present study, the average distance between the holes can be displaced to $d_{\mathrm{MA}}$. Therefore, superior stretch-flangeability of steels B and C may be associated with a good balance of the (i) volume fraction and (ii) interparticle path of the MA-like phase.

The combinations of tensile strength and stretch-flangeability of steels D and E were not improved, in spite of the fact that their microstructures were finer than those of steels $\mathrm{B}$ and $\mathrm{C}$. This may be caused by easy void and crack initiation at the matrix/secondary-phase interface by increases in the volume fraction of the MA-like phase.

Note that the retained austenite in steels A through E also played a role in enhancing the stretch-flangeability through suppression of void initiation and coalescence upon hole expansion due to plastic relaxation of localized stress concentration resulting from the strain-induced transformation. ${ }^{2,16)}$

\section{Summary}

The effects of alloying elements on the microstructure, retained austenite characteristics, tensile properties, and formabilities of $0.2 \% \mathrm{C}-1.5 \% \mathrm{Si}-1.5 \% \mathrm{Mn}-0.05 \% \mathrm{Nb} \mathrm{TM}$ steels subjected to an isothermal transformation process at temperatures below $M_{\mathrm{f}}$ were investigated. In addition, the relation- ships between the tensile properties, stretch-flangeability, and metallurgical factors were discussed. Primary results can be summarized as follows:

(1) The microstructures of the alloyed TM steels consisted of a wide lath-martensite structure and a uniform, fine, MA-like phase on the prior austenitic grains, packets, and block boundaries. It was supposed that the retained austenite was mainly located on the narrow lath-martensite boundaries in the MA-like phase. The volume fraction and interparticle path of the MA-like phase respectively increased and decreased with the addition of alloying elements. On the other hand, the retained austenite characteristics and carbide volume fractions were minimally changed by alloying.

(2) The addition of $\mathrm{Cr}$ increased tensile strength, yield strength, and yield ratio. This was caused by the increase in the strain-hardening rate resulting from the increase in the volume fraction of the MA-like phase. The uniform and total elongation and the combination of tensile strength and total elongation were hardly changed by alloying. The reduction of area was significantly decreased by the additions of $\mathrm{Cr}-\mathrm{Mo}$ and $\mathrm{Cr}-\mathrm{Mo}-\mathrm{Ni}$ due to a large amount of MA-like phase.

(3) The additions of $0.5 \% \mathrm{Cr}$ and $1.0 \% \mathrm{Cr}$ significantly improved the combination of tensile strength and stretchflangeability of TM steel. This was mainly caused by a good balance of (i) volume fraction and (ii) interparticle path of the MA-like phase, which refined the sizes of voids and cracks at the matrix/MA-like phase interface on punching and suppressed the void coalescence on hole-expanding.

\section{REFERENCES}

1) V. F. Zackay, E. R. Parker, D. Fahr and B. Bush: Trans. Am. Soc. Metall., 60 (1967), 252.

2) M. Murata, J. Kobayashi and K. Sugimoto: Tetsu-to-Hagané, 96 (2010), 84 (in Japanese).

3) J. Kobayashi, D. Ina, N. Yoshikawa and K. Sugimoto: ISIJ Int., 52 (2012), 1894.

4) J. G. Speer, D. V. Edmonds, F. C. Rizzo and D. K. Matlock: Solid State Mater. Sci., 8 (2004), 219.

5) B. C. De Cooman and J. G. Speer: Steel Res. Int., 77 (2006), 634.

6) W. Cao, J. Shi, C. Wang, L. Xu, M. Wang, Y. Weng and H. Dong: Proc. ICAS 2010, Metall. Ind. Press, Beijing, (2010), 19.

7) K. Sugimoto and J. Kobayashi: Proc. MS\&T'10, MST, Warrendale, PA, (2010), 1639.

8) J. Kobayashi, S. Song and K. Sugimoto: ISIJ Int., 52 (2012), 1124.

9) J. Kobayashi, K. Sugimoto and G. Arai: Adv. Mater. Res., 409 (2012), 696.

10) J. Kobayashi, D. V. Pham and K. Sugimoto: Steel Res. Int., (Special Edition; ICTP2011) (2011), 598.

11) J. H. Hollomon and L. D. Jaffe: Trans. Am. Inst. Min. Metall. Eng., 167 (1946), 601.

12) H. Maruyama: J. Jpn. Soc. Heat Treat., 17 (1977), 198 (in Japanese).

13) D. J. Dyson and B. Holmes: J. Iron Steel Inst., 208 (1970), 469.

14) O. Umezawa: J. Jpn. Inst. Light Met., 50 (2000), 86 (in Japanese).

15) C. Wang, Y. Zhang, W. Cao, J. Shi, M. Wang and H. Dong: Sci. China Technol. Sci., 55 (2012), 1844.

16) K. Sugimoto, T. Iida, J. Sakaguchi and T. Kashima: ISIJ Int., 40 (2000), 902.

17) D. P. Koistinen and R. E. Marburger: Acta Metall., 7 (1959), 59.

18) T. Sakaki, K. Sugimoto and T. Fukuzato: Acta Metall., 31 (1983), 1737.

19) K. Sugimoto, T. Sakaki, T. Fukuzato and O. Miyagawa: Tetsu-toHagané, 71 (1985), 994 (in Japanese).

20) G. E. Dieter: Mechanical Metallurgy (SI Metric Edition), McGrawHill Book Co., London, UK, (1988), 262.

21) F. A. McClintock: J. Appl. Mech., 35 (1968), 363. 